\title{
TESTS OF APPLICANTS FOR ADMISSION TO UNIVERSITY OF MINNESOTA MEDICAL SCHOOL
}

\author{
M. E. HAGGERTY \\ Unioersity of Minnesota
}

Candidates for entrance to the University of Minnesota Medical School in September, 1916, were given two tests with a view to determining mental capacity and general mental fitness to pursue the work of the school. The tests were given not so much for the purpose of accepting or excluding the immediate applicants as to provide a method and standards for the proper evaluation of future candidates. Since similar tests are being repeated with students applying for admission in September, 1917, the present paper should be regarded as a report of an investigation in progress.

No applicants were examined who did not meet the academic requirements for entrance to the Medical School. These requirements are substantially as follows: A high school course including two years of Latin, two years of prescribed and elective studies in the College of Science, Literature and the Arts in the University of Minnesota or its equivalent. During these two years of work the following studies are prescribed: rhetoric, 6 credits; physics, 8 credits; general chemistry and qualitative analysis or these subjects combined with organic chemistry. 12 credits; zoology, 6 credits; and a reading knowledge of German.

\section{THE TESTS}

Two types of tests were given. One was an omnibus test fashioned after the one reported by Scott.* This test was arranged in triplicate since the students were tested on different days and it was desired, so far as possible, to prevent communication from one group to another.

As a second test, sets $9,91 / 3$, and $10 \mathrm{I} / 3$ of the Thorndike Improved Scale for Reading Ability, Scale Alpha 2, were used.

\section{METHODS OF TESTING}

The candidates, 93 in all, were tested either individually or in groups ranging up to 25 . Both the omnibus test and reading test

\footnotetext{
*Scotr, W. D., The Scientific Selection of Salesmen. Advertising and Selling Magazine, 1916.

†THORNDIKE, E. L., An Improved Scale for Measuring Ability in Reading. Teachers' College Record, November, 1915, and January, 1916.
} 
were given at one sitting. The former was given first and the paper was handed in before the reading test was given out. Accurate time was kept on both tests.

\section{SCORING}

The tests were scored both for rate and quality. In the omnibus tests each error was penalized by adding ten seconds to the raw time. thus giving a "weighted time." The three omnibus tests were rated as of the same difficulty. Subsequent studies with the same tests on approximately 2000 high school students show that there was no substantial error in so doing. In the reading tests the subjects were credited with the values achieved on the Thorndike scale as well as being scored for time. The Thorndike values are called "quality of reading" in the discussion to follow.

\section{RESULTS}

At the time the tests were given there were no data available to show what high or low scores in either of the tests signify in terms of probable success in the work of a medical curriculum. Common sense indicates that in a course as crowded as that of the medical school the quality and rate achieved in difficult reading would be an important indication of probable success in that course. Certain experimental evidence indicates that the rate of ordinarily difficult associations is some indication of general intelligence. That the two tests measure in part the same functions is indicated by the correlation between them of .34 (weighted time in association and quality of reading. (See Table I).

This same correlation figure indicates that in part the two tests measure different things. It was thought, therefore, that a high rank in the two tests would be a double indication of superior ability and would clearly indicate the acceptability of the applicant. Low rank in both tests would argue for rejection on the basis of mental incompetence. Exception to this general rule was made in the case of two students, one Russian and one Hindu, whose language difficulties were inordinate. As a matter of fact no students were rejected wholly on the basis of the tests, as there was always "corroborative evidence" of low ability from the academic records and general information tests.

Of the 93 persons taking the tests, 69 were accepted for entrance and actually entered the medical school in September, 1917. Concerning these we have now available the records for the work of the first semester in the medical school. These records together with the pre-medical record in the academic college and the two tests are the basis of the following table of correlations. 
TABLE I.

\begin{tabular}{|c|c|c|c|c|c|c|c|c|c|c|c|c|}
\hline & 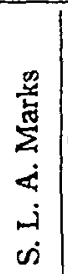 & 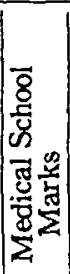 & 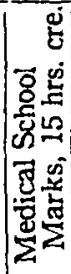 & 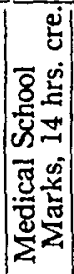 & 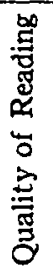 & 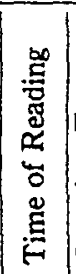 & 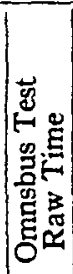 & 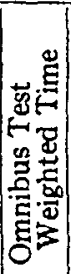 & 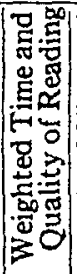 & 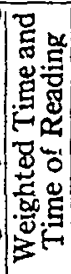 & 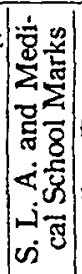 & 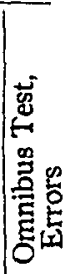 \\
\hline S. L. A. Marks & & 49 & 59 & 51 & 46 & --14 & 39 & 35 & 55 & 36 & 85 & 36 \\
\hline $\begin{array}{l}\text { Medical School Marks } \\
\text { Medical School Marks, }\end{array}$ & 49 & & & & 62 & 24 & 51 & 60 & 65 & 57 & 85 & 29 \\
\hline $\begin{array}{cc}15 \text { hrs. cre } & \ldots \\
\text { Medical School Marks, }\end{array}$ & 59 & & & & 77 & 24 & 68 & 53 & 81 & 61 & 88 & 17 \\
\hline 14 hrs. cre .. & 51 & & & & 56 & 4 & 46 & 47 & 69 & 43 & 85 & 45 \\
\hline Quality of Reading & 46 & 62 & 77 & 56 & & 21 & 41 & 34 & 82 & 41 & 55 & 36 \\
\hline Time of Reading & -14 & 24 & 24 & 4 & 21 & & 19 & 10 & 17 & 76 & 4 & -18 \\
\hline $\begin{array}{c}\text { Omnibus Test, } \text { Raw } \\
\text { Time } . . \\
\text {. }\end{array}$ & 39 & 51 & 68 & 46 & 41 & 19 & & & & & & 39 \\
\hline $\begin{array}{c}\text { Omnibus Test Weight- } \\
\text { ed Time.... }\end{array}$ & 35 & 60 & 53 & 47 & 34 & 10 & & & & & & 67 \\
\hline $\begin{array}{c}\text { Weighted Time and } \\
\text { Quality of Reading. }\end{array}$ & 55 & 65 & 81 & 69 & 82 & 17 & & & & & & 51 \\
\hline $\begin{array}{c}\text { Weighted Time and } \\
\text { Time of Reading. }\end{array}$ & 36 & 57 & 61 & 43 & 41 & 76 & & & & & & 33 \\
\hline S. L. A. and Medical & & & & & & & & & & & & \\
\hline School Marks. . & 85 & 85 & 88 & 85 & 55 & 4 & & & & & & 25 \\
\hline Omnibus Test Errors. & 36 & 29 & 17 & 45 & 35 & $|-18|$ & 39 & 67 & 51 & 33 & 25 & \\
\hline
\end{tabular}

For a proper understanding of this table some explanation of terms is necessary. "S. L. A. marks" means the quality of work done by the student in his college course prior to his entrance to the medical school. In the University of Minnesota the grades which a student receives carry what are called "honor points." Grades of $\mathrm{A}, \mathrm{B}$, and $\mathrm{C}$ merit three, two, and one honor points respectively. A grade of $\mathrm{D}$ or below carries no honor points. A student must have an average of one honor point per credit hour to receive a degree from the University. In computing the "S. L. A. marks" in this study the total number of honor points made by a student was divided by his number of credits. These marks therefore indicate the average quality of work done by the student in his pre-medical course. In no case was the amount of such academic work less than two full years. From this it ranged up to four years, credited with the bachelor's degree. Sixty-eight cases were available for correlation. 
"Medical marks" are the marks received by the student during the first semester in the medical school. Only students carrying full work, 14 or 15 credit hours, were considered. The difference in number of credits was determined by the fact that some students took organic chemistry, a four-hour course, and others took physiological chemistry, a three hour course. There were a considerable number of irregular students; some had secured medical school credits during their pre-medical courses; others did not carry full work in the medical school during the semester in question All such students were excluded in figuring correlations. The number available for correlations were 24 with fifteen credits and 26 with fourteen credits or 50 in all.

In figuring the correlations it was desirable to credit quality as well as quantity of work. Since a very large number of students were reported with marks of $D$ which carried no honor points at all it was clearly unfair to use the same method of figuring quality of work as was used on the "S. L. A. marks." Accordingly the following arbitrary values were assigned to the several letters:

$$
\begin{array}{lllll}
A=10 & B=8 & C=5 & D=2 & F=0
\end{array}
$$

The "medical school marks" were computed by finding the number of such points to which a student was entitled and dividing the number by the number of credits. Thus: 3 credits $A=30$ points, 5 credits $B=40$ points, 6 credits $\mathrm{D}=12$ points, a total of 82 points. This total divided by 14 , the number of credits, equals 58.5 , the actual mark of quality to which the student is entitled. By this method the 15 credit and 14 credit students may be considered together without serious statistical error.

"Quality of reading" means score on Thorndike scale. "Time of reading" means total time required for reading test. "Omnibus Test: Raw time" equals time required for the association test. "Omnibus Test: Weighted time" is the same with 10 seconds added for each error. Available for correlation in all of these measures were 68 cases.

It was originally thought that the weighted time in the omnibus test and the quality of reading would be the best prognostic measures, and the applicants were rated in them first. As it turns out the correlation of these combined measures with the marks subsequently made by these students is .65 for the group of $50, .81$ for the fifteen-credit cases and .69 for the 14 credit cases. Either of these tests alone gives a slightly lower but still substantial correlation. In no case is it less than .56 . 
A comparison of the correlations of S. L. A. marks and medical school marks shows that the tests were a much better indication of ability to do the work of the medical school than were the academic records of these applicants. There is not a single case in which the test correlations are so low as the academic mark correlations. In fact either test alone is a better prognostic measure than were the S. L. A. marks. The "quality of reading" correlates with medical marks to the extent of .62 , the omnibus test to .60 and the two combined to .65, while the S. L. A. marks show but .49 .

The prognostic value of the tests may be seen also from the per cent of median, tertile and quartile retention which turns out to be 71 , 56 and 46 respectively as shown in Figures 1,2, and 3 . Thus in Figure 1,23 persons are shown to stand in the upper half of the group in both of the tests and in the upper half of the group in medical school marks; 16 persons stood in the lower half of the group in both the tests and medical school marks. Nine persons were in the first half in the tests but in the latter half in school marks, while 2 were in the lower half in the tests but in the upper half in school marks. From Figure 3 it is apparent that no person who fell to the second or third quartile in the tests achieved a place in the first quartile in school marks. Only two in the second quartile of the tests came into the school mark first quartile. On the other hand no person who achieved a first quartile in the tests fell to the fourth quartile in school marks. But two of this test group went to the third quartile while 6 are found in the second and 10 in the first quartile. Only 9 of the 50 individuals are displaced in the marks more than one quartile from their test rankings. Such displacement as does exist is largely due to the very great number of D's given in the anatomy courses.

As in the case of the correlations, the median, tertile and quartile retentions show the tests, either singly or combined, to have been better prognostic instruments than the academic records of the students in the Arts college. 
FIGURE 1.

Median Retention

RANKS IN MEDICAL SCHOOL MARKS

Halves

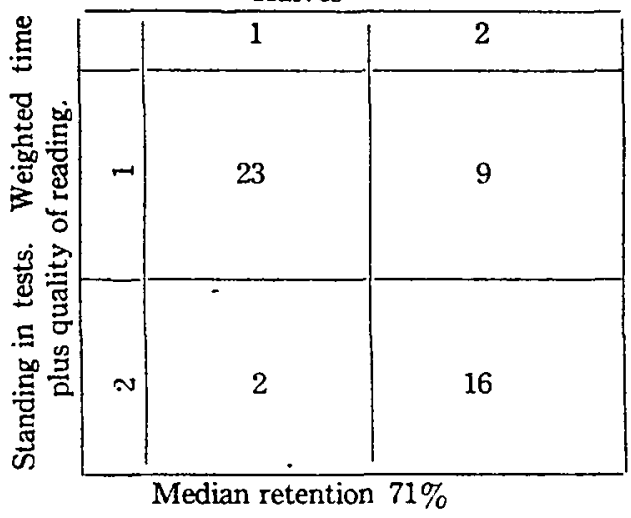

These results are significant. They mean that an entrance examination board can determine by three hours work the fitness of one hundred applicants for the work in a medical school more exactly than they can derive such information from the laborious examination of academic records, often hard to obtain and equivocal in meaning.*

A curious fact is the somewhat equivocal correlations shown by the "time of reading" scores with academic marks. With the S. L. A. marks it is -14 and with medical school marks it is positive .24. From this it would seem that in a test as difficult as the reading scale the time consumed is no indication of ability. This was not true of the association test where the "raw time" scores gave positive correlations of .39 and .51 with S. L. A. and medical school marks, .68 and .46 with the 15 and 14 credit student's marks and .41 with the quality of reading. This probably means that in the simpler associations the rate is more important than in the more difficult tests and more important than the quality of work as measured by the errors in this test.

It is probably fair to interpret all these results as follows: As a means of prognosis for success in the medical school course, it is

*The giving of the two tets occupied the time of two examiners for not to exceed one and one-half hours. Since the applicants may be tested in groups, a hundred may be examined at a sitting. The scoring of the tests may be done very rapidly by persons familiar with the work. 
FIGURE 2.

Tertile Retention

RaNKS IN MEDICAL SCHOOL MarkS

Tertiles

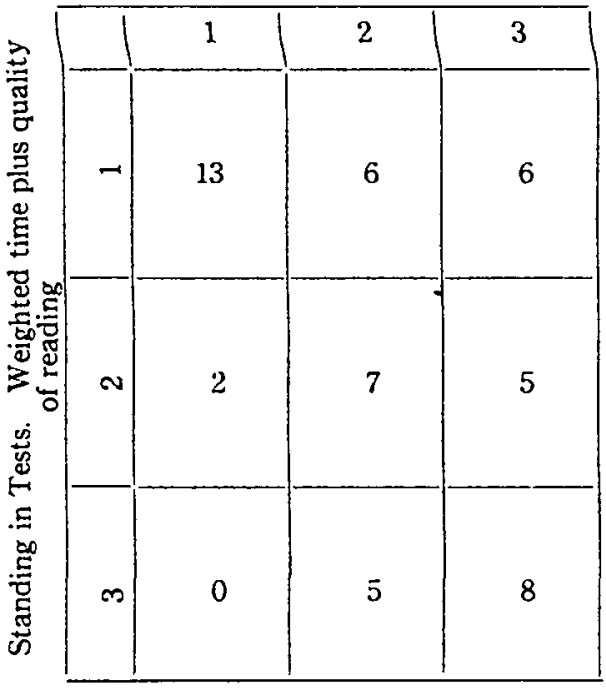

Tertile Retention $56 \%$

FIGURE 3.

Quartile Retention

Ranks in MEdical SchOOL Marks

Quartiles

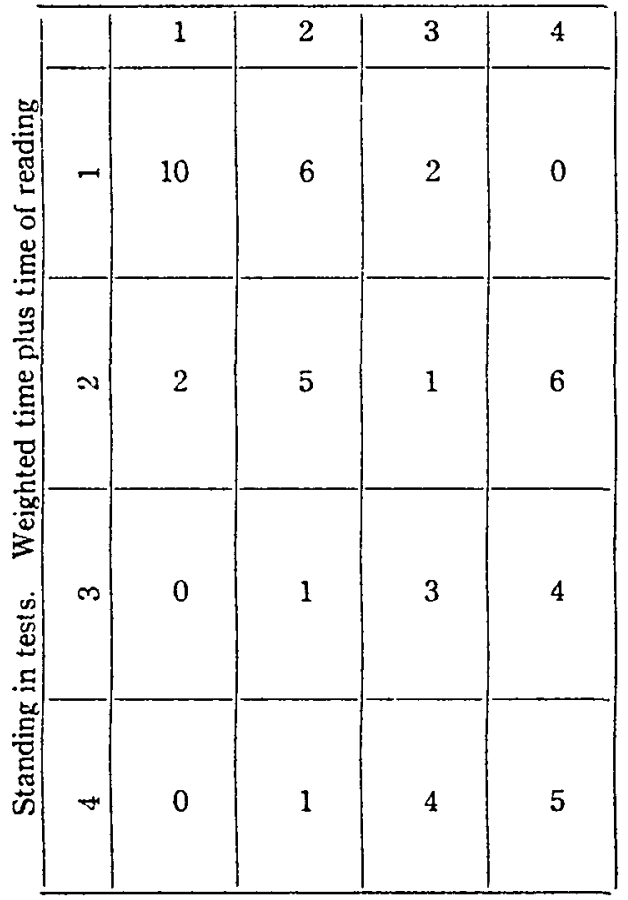


important to know the rate and quality of fairly simple associative processes (weighted time in omnibus test) and also to know how difficult an associative problem a student can master more or less regardless of the time required to do it (quality of reading).

The desirable amount of correlation between mental tests and academic achievement is difficult to fix. Success in school work is apparently dependent upon many factors, such as good observational powers, memory, imagination and intelligence or reasoning capacity. Presumably such tests as the ones here used are directed to the measurement of such intellectual functions. Beyond these, however, are other mental functions such as industry, endurance, interest, persistence of motive, freedom from prejudice, physical fitness, general tonicity of muscular system, and a wide range of instinctive and emotional states and activities illy defined but fairly described as "attitudes," "sets," etc. It these tests measure merely the intellectual functions, then a certain portion of the student's mark is due to mental abilities not evaluated by the tests. In such cases the correlation should fall below 1, or a perfect figure. The amount it falls short would be determined by the degree to which such non-intellectual functions determine the school mark. In such cases, a correlation figure of $.60, .70$ or .80 might be as high as could be expected and should be regarded as the maximum to be expected from tests of this type. In case .80 were determined as such maximum, a correlation of .60 with a test for intellectual functions would be explained as due to the inadequacy of the test for the measurement of such functions. In such case it would be necessary to improve the test or to supplement it with other tests for intellectual capacities. With the fixed maximum of .80 a test showing .80 would be regarded as serving all the legitimate ends of the intellectual test. Its proper supplement would be tests for the instinctive, emotional and other factors to which a certain portion of the student's mark is due.

It is extremely doubtful, however, whether such vivisection of mental capacities is the way to their proper evaluation. Association in an individual is not the abstract thing we talk about in our text books but is shot through with the very interests and emotions we so carefully discriminate it from in our discussions. When a person attacks the "hard directions". test it is not merely the abstract processes of association, memory, discrimination, and attention which are involved. It is all of these modified by the desire to suc- 
ceed, to do the task quickly, to obviate errors, and suffused with the affective and emotional states prompted by the surprise, absurdity and complexity of the test. The time score recorded at the end of the test is, therefore, a measure of the complex mental state involving all of these functions. Similarly, when an individual works diligently for 30 minutes on the Thorndike reading scale it is not fair to assume that the result of his work is merely an intellectual product. It is a mental product measuring his intellectual capacities, to be sure, but also indirectly testing his interest, his endurance, persistence and other emotional and instinctive attitudes. The implication of those considerations is that a correlation of .70 between a test and school marks means that the test measures more than the intellectual factors operating to produce the marks'but measures them all partially. It means further the possibility of a test which will correlate much higher with actual performance than would be the case if the test were of purely intellectual functions. Conceivably the correlation could approach a perfect relationship. This means that none of the measures available from these tests is a satisfactory one. Valuable as they are it is probable that they may be improved so as to yield even higher correlations than the ones here reported. Two changes, on the basis of experience, seem worth while. The reading test should be presented with more degrees of difficulty so as to distribute the individuals more widely. The association test should be made of more uniform difficulty throughout. This means that some substitution should be made for the first three parts which are apparently so easy for students of the advancement of those here considered that the mechanical performance of writing the answers consumes more time than the mental processes of thinking the correct response.

In the testing of the students applying for entrance to the Medical School in September 1917 these changes have been made. The value of these changes is yet to be determined. 